possess different epidemiological characteristics.

DR A E LE FAOU

Laboratoire de Bactériologie,

Faculté de Medecine,

Strasbourg, France
BOTTLAENDER

M BOTTLAENDER
BOtalier Frédéric Joliot,

Service Hospitalier Frédéric Joliot,
Département de Biologie du CEA,

Orsay, France.

J-CTARDIEU

Dispensaire Antivénérien,

Clinique Dermatologique,

Hôpital Civil,

Strasbourg, France

Corresponding author: Dr A E Le Faou, Laboratoire de Bacteriologie, Faculté de Médecine, 3 rue Koeberlé, 67000 Strasbourg, France

1 Van de Laar MJW, Pickering J, van den Hoek JAR, van Griensven GJP, Coutinho RA, van de Water HPA. Declining gonorrhoea rates in The Netherlands, 1976-88: consequences for the AIDS epidemic. Genitourin Med 1990;66:148-55.

2 Le Faou A, Guy I, Riou J-Y. Auxotypes et sensibilité à 6 antibiotiques des souches de Neisseria gonorrhoeae isolées à Strasbourg en 1977-1978. Ann Dermatol Vénéréol (Paris) 1979, 106:267-72.

3 Sivakumar K, Basu Roy R. Falling prevalence of Chlamydia trachomatis infection among female patients attending the Department of Genitourinary Medicine, Bournemouth. Genitourin Med 1990;66:400.

4 Shanmugaratnam K, Pattman RS. Declining incidence of Chlamydia trachomatis in women attending a provincial genitourinary medicine clinic. Genitourin Med 1990;66:400.

Female paraurethral ducts and glands as the sites of agents of sexually transmitted diseases

Female paraurethral (Skene's) ducts and paraurethral glands (PUDG) and the male prostate are morphologically and functionally identical organs, as has been proved by excellent studies of Zaviačič et al. ${ }^{1-6}$ Thus, PUDG and the male prostate could both be affected with inflammatory changes caused by sexually transmitted agents. We report two cases of female "prostatitis" of trichomonad aetiology.

The first case was a 26 year old waitress, multipara $\times 2$, married. Two years previously she had been treated, together with her husband, for trichomonas vaginitis with metronidazole $2.0 \mathrm{~g}$ orally in a single dose. Since then she reported repeated swelling of the vaginal wall in the location of the PUDG and urethra. After pressure on this area, pus was expressed from the urethra. The condition was accompanied by dysuric symptoms. Lactobacillus species and coagulase negative staphylococci were isolated from vaginal culture using Thayer Martin medium, Sabouraud glucose agar, MacConkey's agar and trichomonas medium (Oxoid). After opening of the urethral meatus, to a depth of $4 \mathrm{~mm}$ from the margin of the external orifice of the female urethra, the orifices of the PUDG were examined colposcopically, enlarged 12.5 times and appeared as two symmetrically set pointed orifices with inflammed margins and fibrin residue. After pressure on the vaginal wall against the urethra in the direction from the depth of the urethra to the external orifice of the urethra, $5 \mathrm{ml}$ of pus from PUDG were expressed. From the pus culture using the same culture media, Streptococcus agalactiae was isolated. The patient was treated for 10 days with ampicillin $3.0 \mathrm{~g}$ daily in accordance with the sensitivity. The process recurred and a postinflammatory obliteration of the PUDG lumina developed. Owing to retention of the contents a painful swelling the size of a hen's egg occurred in the proximal third of the vagina and PUDG orifice. The white blood cell count was $12.1 \times 10^{9} / 1$ and erythrocyte sedimentation rate was $50 \mathrm{~mm}$ in one hour. Transvaginal surgical extirpation of the tumour was necessary.

After incising the abscess cavity, Trichomonas vaginalis and Streptococcus agalactiae were isolated from pus by culture. Histological examination proved that the abscess cavity was a dilated, inflamed, paraurethral gland with postinflammatory obliteration of the duct. Thanks to a 10 day treatment with ampicillin $2.0 \mathrm{~g}$ daily and metronidazole $750 \mathrm{mg}$ daily the inflammation has been successfully controlled.

The second case was a 43 year old female worker, with three children, divorced. She stated that she last had sexual intercourse a year previously when she was treated for trichomonas vaginitis by metronidazole $2.0 \mathrm{~g}$ orally in a single dose. The PUDG inflammation, similar to that in the first case, was clinically manifested by painful swelling of the proximal third of the vagina in the location of the PUDG lumen, with dysuric problems and subfebrile states, with no changes in leukocyte count or erythrocyte sedimentation rate. Lactobacillus sp., Eubacterium lentum and coagulase negative staphylococci were isolated from vaginal culture. Under colposcopic control, enlarged 12.5 times, probing of the PUDG duct broke the adhesions, and after pulling out the probe from a depth of about $0.5 \mathrm{~cm}$, approximately $4 \mathrm{ml}$ of pus spontaneously flowed out through the orifice of the PUDG. From the pus culture Trichomonas vaginalis was isolated. After a 10 day treatment with ampicillin $2.0 \mathrm{~g}$ daily and metronidazole $750 \mathrm{~g}$ daily the inflammation resolved without surgical intervention.

These cases of PUDG inflammation of trichomonad aetiology indicate that the "female prostate" can be one of the sites of STD. Furthermore, this localisation can also be the cause of relapsing STD.

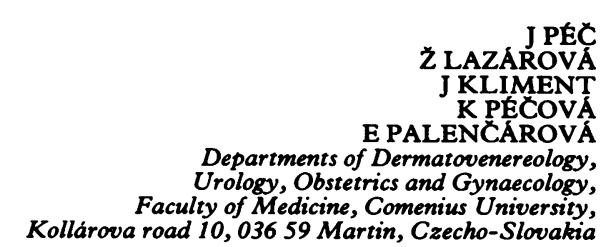


1 Zaviačič M, Brozman M, Holomán̆ IK, et al. New information on the paraurethral (Skene's) ducts and glands in the female. Bratisl Lek Listy 1983;79:533-44.

2 Zaviačič M, Jakubovsky J, Polák S, et al. The fluid of female urethral expulsions analysed by histochemical electronmicroscopic and other methods. Histochem J 1984;16:445-7.

3 Zaviačič M. Enzyme histochemistry of the adult human female prostate: acid phosphate distribution. Cell Mol Biol 1984;6:545-51.

4 Zaviačič M. Enzyme histochemistry of the adult human female prostate: hydrolase and dehydrogenase distribution. Cell Mol Biol 1984;6:537-43.

5 Zaviačič $M$. The adult human prostata homologue and the male prostate gland: a comparative enzyme-histochemical study. Acta Histochem (Jena) 1985;77:19-31.

6 Zaviačič M, Brozman M, Zajičková $M$, et al. The adult human female urethra enzyme-histochemical study. Acta Histochem (Jena) 1985;77:165-75.

\section{Treatment of genital herpes with chlorous acid releasing gel}

In an open study, a chlorous acid releasing gel (Allay gel, Alcide Corporation), with in vitro activity against herpes simplex virus was shown to have efficacy in the treatment of initial genital herpes. ${ }^{1}$

We have conducted a double blind, multiple crossover randomised trial to assess the efficacy of this preparation when compared with a placebo in the treatment of recurrent genital herpes. The study was conducted at the Praed Street Clinic, St Mary's Hospital, and prior approval of the district ethics committee was obtained.

We studied 100 patients (56 female, 44 male) during one to four episodes each. Patients were excluded if they were pregnant or lactating, known to be HIV positive, or had used antiviral drugs or immune modulators within 14 days of admission to the study. All patients had had at least one virologically confirmed episode of genital herpes before admission to the study and other concurrent infections were excluded by conventional techniques on enrolment.

Each patient was fully counselled and gave written informed consent. The technique of administration, which involved the mixing of the contents of two sachets before application to the lesions, was explained and the patients asked to apply the treatment twice daily for seven days. Each patient was asked to keep a record of symptoms and an assessment was made by the investigators on days $1,2,3-5$ and 8 . At the completion of each episode, the patient was supplied with treatment for the next episode and asked to start therapy only if this could be achieved within 6 hours of the onset of symptoms. Treatment for the first two episodes and the second two episodes were randomised to active or placebo preparation separately so that each patient received active drug for either the first or the second episode.

Only 49 patients completed two or more episodes. No significant difference in time to healing or duration of viral shedding was noted when the first two episodes were compared in these patients. Similarly when all placebo treated episodes were compared with all Allay gel treated episodes there was no significant difference (table) in the healing time or duration of viral shedding. However, in male patients the mean duration of viral shedding was shorter in patients treated with the active preparation although this did not reach statistical significance. For most parameters, the placebo preparation appeared to perform marginally better than the active preparation.

Patients treated with the active preparation noted more adverse events ( 13 vs 2 ) and in three patients bleaching of the pubic hair was noted. The treatment was unpopular with many patients, which may have accounted for the poor recruitment and high dropout rate in this study.

These data demonstrate that Allay gel is unlikely to be of benefit in the management of recurrent genital herpes, at least in its present format. This contrasts with the results of a previous open study in which benefit was suggested in the management of initial genital herpes. One possible explanation may be that in initial genital herpes viral shedding may be prolonged and the anti-viral effect of the preparation useful. In recurrent herpes, when viral shedding may only be transient, the application of an acidic gel may delay healing.

$$
\begin{array}{r}
\text { F E RUCK } \\
\text { A BANKS } \\
\text { P E MUNDAY } \\
\text { The Jefferiss Wing, St Mary's Hospital, London W2 1NY, UK } \\
\text { R D KROSS } \\
\text { Alcide Corporation, } 99 \text { Sherwood Avenue, Farmingdale, } \\
\text { New York } 11735 \text { US }
\end{array}
$$

\begin{tabular}{|c|c|c|c|c|}
\hline \multirow[b]{2}{*}{ Treatment } & \multicolumn{2}{|c|}{ Time to healing (days, ( $S D$ )) } & \multicolumn{2}{|c|}{ Duration of viral shedding (days, $(S D)$ ) } \\
\hline & Males (44) & Females ( 56 ) & Males (44) & Females ( 56 ) \\
\hline $\begin{array}{l}\text { Allay gel } \\
\text { Placebo }\end{array}$ & $\begin{array}{l}6 \cdot 12(2 \cdot 47) \\
5 \cdot 47(2 \cdot 59)\end{array}$ & $\begin{array}{l}5 \cdot 65(2 \cdot 25) \\
5 \cdot 23(2 \cdot 85)\end{array}$ & $\begin{array}{l}1.85(1.25) \\
3.50(2.67)\end{array}$ & $\begin{array}{l}2.53(1.77) \\
2.87(2.13)\end{array}$ \\
\hline
\end{tabular}

1 Lawrence AG. Treatment of herpes genitalis with new topical agent, Allay gel. Genitourin Med 1988;64:395.

Accepted for publication 15 July 1991

Table Time to healing and duration of viral shedding in patients treated with Allay gel or placebo 